Professor Malin SONG, PhD

Anhui University of Finance and Economics

E-mail: songmartin@163.com

Shuhong WANG, PhD (Corresponding author)

Ocean University of China

E-mail: shwang01@ sina.com

Professor Tomas BALEŽENTIS, PhD

Lithuanian Institute of Agrarian Economics

E-mail: tomas@laei.lt

\title{
BIASED POLICY, HUMAN CAPITAL DISTRIBUTION AND GREEN TECHNICAL PROGRESS
}

\begin{abstract}
As biased policies lead to low efficiency of resource allocation and waste, this study compares the operating environment of state-and non-stateowned enterprises, and confirms the distortion of human capital distribution in these two types of enterprises caused by biased policies. Further, this study verifies the decline of the green technology progress rate resulting from distribution distortion, concluding that market competition can improve human capital distribution efficiency, but this effect declines due to a biased policy environment. Specifically, there is a U-shaped relationship between market competition and green technology: weak market competition is not favorable to green technology progress and vice versa.
\end{abstract}

Keywords: biased policy, human capital distribution, green technology progress, market competition.

\section{JEL Classification: C21, 044}

\section{Introduction}

Different types of enterprises can enjoy different policies, creating a biased policy environment, an essential feature of microeconomic operations in China. Biased policies are reflected most significantly in state- and non-state-owned enterprises, their direct result being low resource allocation efficiency (Brandt et al., 2013). The 2003 Report of Provincial Business Operation Environment Index in China pointed out that the operational environment of non-state-owned enterprises was inferior to that of state-owned ones, and the differential policy or governmental administrative treatments among different types and sizes of enterprises formed enterprise-type-based biased policies. These include not only direct intervention

DOI: 10.24818/18423264/53.1.19.16 
and assistance, but also hidden subsidies such as financial repression, low resource tax, and having a corner on the market.

Recently, China has been in a New Normal state that superposed three stages, namely shift of growth rate, throes of structural adjustment, and absorption of incentive policies. The existing middle and low growth rate periods will not change in the short term (Song et al., 2016). Meanwhile, the damage to natural resources and the environment in China is increasing. In this context, some scholars have pointed out that green technology progress is an important driving force to stimulate economic growth and improve environmental quality (Song \& Wang,2016). Moreover, the state-owned enterprises that reflect the national direction and are supported by biased policies should save energy and reduce emissions to stimulate the development of green technologies. However, according to an article published by Reuters in 2013, large-sized state-owned enterprises were still seeking profit, while environmental protection was compared to taking pills, ${ }^{1}$ indicating that state-owned enterprises had not made green technology progress their focus.

Actually, it was not a lack of interest from state-owned enterprises, but the fact that they did not find the key determinant to improving green technology. Therefore, research on environmental efficiency (Zhang \& Choi, 2014; Fang et al., 2018), environmental regulation (Song \& Wang, 2016; Qi, Li, 2017; Zhao et al., 2017), biased technology (Acemoglu et al., 2015), and resource carrying capacity (Wang et al., 2017; Zeng, 2017) has been carried out.

Results on green technology improvement are limited, despite extensive research. A possible reason may be the distribution efficiency of human capital, as the successful implementation of any strategy or policy requires considering resource allocation efficiency and the effective distribution of resources as their objective, which is also a fundamental function in an economic system (Wurgler, 2000). Human capital is the key factor representing both efficiency improvement and technological progress. If human capital is not effectively distributed, enterprises with low efficiency may have more human capital than needed and exist for longer on the market, which will result in resource misallocation within or between industries (Jones, 2011). For example, for state-owned enterprises, market uncertainty is low and financing easy. Accordingly, they are not interested in carrying out research and development (R\&D) activities for energy saving and emission reduction (Chiara, 2011). Conversely, many non-state-owned enterprises emphasize green technology development to reduce pollution costs, as they have neither human capital advantages nor policy preferences.

With the deepening of marketization in China, the "survival of the fittest" rule of market competition stimulated innovation and technological progress and vitalized

\footnotetext{
${ }^{1}$ Please refer to http://money.163.com/13/0401/08/8RC5L3PJ00251LK6.html for further details.
} 
Biased Policy, Human Capital Distribution and Green Technical Progress

industrial development. The second issue is whether biased policy is unfavorable to human capital distribution, and will further lead to slowing down green technology progress, and whether market competition can improve this condition. These issues will be examined in this study. The second section of this paper reviews relevant literature, the third section proposes the theoretical models, the fourth section presents the empirical analysis, and the final section presents conclusions and policy suggestions.

\section{Literature Review}

Biased policies influence the technology progress rate in two ways: the normal evolution and input factor allocation of an enterprise. First, bias towards state-owned enterprises makes low-efficiency state-owned enterprises unable to exit the market timely, and highly efficient non-state-owned enterprises unable to enter the market smoothly. When this happens, production factors cannot flow properly and large quantities of production resources cannot be fully utilized (Hsieh \& Klenow, 2009). Second, the different prices of human capital distort enterprises' choices of inputs. The prices of material resources are low for stateowned enterprises, while those of human capital are high, which is equivalent to a situation in which investment in material resources is subsidized, and the utilization of human capital is taxed (Brandt et al., 2012). Consequently, stateowned enterprises may rather choose to substitute material resources with human capital input, leading to a deviation from the optimal input level and slowing down the technological progress rate. Hsieh and Klenow (2009) predicted that, if efficiency of human capital distribution in China improved to the US level, China's macroeconomic output would increase by $30 \%$ to 50\%. Brandt et al. (2012) further pointed out that, if human capital flowed from low-efficiency state-owned enterprises to high-efficiency private enterprises, the technology progress rate of Chinese enterprises would greatly increase. As such, market competition is considered as an effective measure to stimulate human capital flow (Dimelis\&Louri, 2002).

There are different views on the relationship between market competition and technological progress. Dodgson and Rothwell (1994) indicated that the R\&D of state-owned enterprises was more active than that non-state-owned ones, as the former would not adopt the strategy of no R\&D despite its high costs and uncertainty. Sunku (2010) considered that enterprises faced with high competition would enhance investment in $\mathrm{R} \& \mathrm{D}$, while the bureaucracy in many monopolistic enterprises, especially large-sized state-owned enterprises in China, would be an obstacle to R\&D activities. Sunku (2010) further compared monopoly and competitive markets, and considered that market competition made it easier for enterprises to innovate while monopoly was conducive for sustaining original production plans. Chiara \&Ivete (2011) analyzed the business data of Luxembourg 
Malin Song, Shuhong Wang, Tomas Baležentis

and found that under monopoly conditions, there was no practical motivation for an enterprise to launch $R \& D$. Hence, the replacement risk resulting from delaying $R \& D$ would be higher than the cost of saving $R \& D$ expenses. In this case, enterprises would choose to carry out $R \& D$ activities. When the competition degree exceeds a certain threshold value, enterprises would thus reduce $R \& D$ activities to avoid $R \& D$ losses resulting from rapid technological substitution.

In the above literature, scholars' definitions of $R \& D$ are based on the $R \& D$ of productive technology, with no mention of green technology. However, the $R \& D$ of green technology will incur certain costs, but will not bring any positive output to enterprises. Therefore, for many profit-seeking enterprises, although they have the motivation to carry out R\&D activities, they will choose productive technology over green technology. If green technology $R \& D$ is considered, the research conclusions of the above studies may be different. Unfortunately, few studies have hitherto estimated the relationship between market competition and green technology. The main reasons for that are as follows. (1) There are numerous determinants of green technology. If market competition will stimulate human capital flow from low-efficiency state-owned enterprises to highly efficient private ones and further influence green technology, then biased national policies would hinder the occurrence of such a flow. (2) There is still no adequate method to measure green technology and the results of different measurement methods vary. In this case, identifying the specific factors that lead to low efficiency of human capital distribution, defining green technology, and calculating the influences of human capital distribution on green technology are key to solving the research objectives put forward by this study.

This study considers that market competition and biased policy are positive and negative feedback mechanisms, respectively, that influence the efficiency of human capital distribution. This means the following two problems need to be solved to accurately estimate the distortion of human capital distribution efficiency in state-owned enterprises. The first is how to measure biased policy and market competition intensity, and the second is how to measure the distortion of these two feedback mechanisms due to green technology..Therefore, we used the "wedge" model of Chari et al. (2007) and the macroscopic measurement framework of Hsieh and Klenow (2009) to measure green technology distortion.

\section{Theoretical models}

\subsection{Measurement of biased policy distortion}

We first assume that the final product production function of representative enterprises is a C-D production function, and the production function of intermediate products in each industry is a D-S production function with constant elasticity of substitution. Then, the enterprise profit function can be expressed as:

$$
\pi_{s i}=\left(1-\tau_{Y_{s i}}\right) P_{s i} Y_{s i}-\left(1+\tau_{L_{s i}}\right) \omega L_{s i}-R K_{s i},
$$


Biased Policy, Human Capital Distribution and Green Technical Progress

where $S$ stands for industry, ${ }^{i}$ refers to enterprises, $\pi$ to enterprise profit, ${ }{ }_{Y}$ is output distortion, ${ }_{L}$ is human capital distortion, $P$ product price, $R$ capital factor price that enterprises face, $\omega$ human capital factor price, and $L$ human capital. At this time, the condition for maximizing enterprise profit is:

$$
\frac{K_{s i}}{L_{s i}}=\frac{\alpha_{s}}{1-\alpha_{s}} \frac{\omega}{R} \frac{1}{\left(1+\tau_{L_{s i}}\right)},
$$

where ${ }^{\alpha}$ refers to the elasticity of human capital output of industry $s$. Then, human capital distribution and output are, respectively:

$$
\begin{gathered}
L_{s i}=\frac{A_{s i}^{\sigma-1}\left(1-\tau_{Y_{s i}}\right)^{\sigma}}{\left(1+\tau_{L_{s i}}\right)^{\alpha_{s}(\sigma-1)}}, \\
Y_{s i}=\frac{A_{s i}^{\sigma}\left(1-\tau_{Y_{s i}}\right)^{\sigma}}{\left(1+\tau_{L_{s i}}\right)^{\alpha_{s} \sigma}} .
\end{gathered}
$$

From this, the distribution of human capital among enterprises not only depends on the competitive environment of enterprises, but also from the degree of distortion of biased policies on enterprises. If the distribution of human capital is affected by a biased policy, then there will be differences between the marginal product value of human capital, input factors of enterprises, and cost. Thus,

$$
M R P L_{s i}=\left(1-\alpha_{s}\right) \frac{\sigma-1}{\sigma} \frac{P_{s i} Y_{s i}}{L_{s i}}=\omega \frac{1}{1-\tau_{Y_{s i}}}
$$

From equation (5),the pre-tax marginal output of enterprises with low competitive intensity is high, while that of enterprises with fierce market competition is low. Subsequently, we can obtain the human capital distortion that enterprises face:

$$
\tau_{L_{s i}}=-1+\frac{\alpha_{s}}{1-\alpha_{s}} \frac{\omega L_{s i}}{R K_{s i}},
$$

Equation(6) indicates that, when enterprises cannot obtain relevant human capital because of the influence of biased policies, $\tau_{L}$ will be high. Conversely, when enterprises benefit from biased policies, $\tau_{L}$ will be low.

Hereinafter, we include both market competition intensity and biased policy in our analytic framework. Assume that state-owned enterprises are influenced by biased policy, and the input of human capital suffers from a serious deviation. We set the output distortion of state-owned enterprises resulting from 
biased policy as $\tau_{P Y}$, distortion of human capital as $\tau_{P L}$, output distortion of stateowned enterprises resulting from market competition as $\tau_{C Y}$, and distortion of human capital as $\tau_{C L}$.Then, the distortion of state-owned enterprises will be the sum of these two types of distortion,

$$
\begin{aligned}
& \tau_{Y_{s i}}=\tau_{P Y}+\tau_{C Y}, \\
& \tau_{L_{s i}}=\tau_{P L}+\tau_{C L} .
\end{aligned}
$$

In the section on empirical analysis, we will adopt propensity score matching (PSM) to match state-owned enterprises with the closest non-state-owned ones,calculating output distortion $\tau_{Y}$ and human capital distortion ${ }^{\tau_{K}}$ for the state of state-owned enterprises under the influence of market competition only to estimate the influence of biased policies on enterprise output and human capital. Next, we adopt a framework of macroeconomic accounting to continue the measurement of distortion by human capital distribution distortion to green technology.

\subsection{Measurement of green technology distortion}

Referring to Hsieh and Klenow (2009), we measured the green technology disturbance led by biased policies. By measuring the rates of green technology progress of enterprises under the influence of biased policy or not we obtain the green technology distortion. However, we first need to define green technology. We use a DEA method to measure green technology progress. Since it comprises energy-saving and emission-reducing products, the literature still lacks a mature and comprehensive measurement method. According to Acemoglu et al. (2015), the production frontier contains deflections, owing to the influences of biased technology progress. Accordingly, we use the slack-based measurement method to simulate the deflection progress of the production frontier. Assume a factor input $\mathrm{X}$ and an energy input $\mathrm{E}$ in base period $\mathrm{S}$ and end period $\mathrm{T}$. Then, the position of the production envelopment surface moves in the direction of $\mathrm{X}$ and Euclidean center A also moves on the envelopment surface. During measurement, we must consider the deflection of Decision Making Unit (DMU) A's position on the production envelopment surface.

Under the same undesirable output, if both input and output in period $\mathrm{T}$ increase compared with those in period S, or under the same input, if output increased while undesirable output decreased and, in the meantime, the production envelopment surface moved toward $\mathrm{X}$, this condition is termed emission-reducing technology progress. In this case, we calculate production technology efficiencies in periods $\mathrm{S}$ and $\mathrm{T}$ by keeping constant the original production technology, that is,

the production frontier $\mathrm{S}$. Therefore, we obtain $\rho_{x}^{s}\left(x_{s}, y_{s}\right)$ and $\rho_{x}^{s}\left(x_{T}, y_{T}\right)$. By keeping the production frontier $\mathrm{T}$ unchanged and calculating the production 
Biased Policy, Human Capital Distribution and Green Technical Progress

technology efficiencies of $\mathrm{A}$ in periods $\mathrm{S}$ and $\mathrm{T}$, we obtain $\rho_{x}^{T}\left(x_{s}, y_{s}\right)$ and $\rho_{x}^{T}\left(x_{T}, y_{T}\right)$. Considering that the changes in the production frontier are mainly caused by those in technology and production efficiencies, if the factors of production efficiency change can be eliminated, then we can derive the change in only production technology efficiency.

As such, the rate of change in production technology efficiency is

$$
D_{x}=\frac{\rho_{x}^{s}\left(x_{s}, y_{s}\right) / \rho_{x}^{s}\left(x_{T}, y_{T}\right)}{\rho_{x}^{T}\left(x_{s}, y_{s}\right) / \rho_{x}^{T}\left(x_{T}, y_{T}\right)} .
$$

Similarly, the rate of change in emission-reducing technology efficiency is

$$
D_{b}=\frac{\rho_{b}^{s}\left(x_{s}, y_{s}\right) / \rho_{b}^{s}\left(x_{T}, y_{T}\right)}{\rho_{b}^{T}\left(x_{s}, y_{s}\right) / \rho_{b}^{T}\left(x_{T}, y_{T}\right)} \text {. }
$$

Therefore, we can set up the Malmquist index of emission-reducing technology progress $(\mathrm{ErBP})$ as

$$
\operatorname{ErBP}=\sqrt{D_{B} / D_{X}}=\sqrt{\frac{\rho_{B}^{s}\left(x_{s}, y_{s}\right) / \rho_{B}^{s}\left(x_{T}, y_{T}\right)}{\rho_{B}^{T}\left(x_{s}, y_{s}\right) / \rho_{B}^{T}\left(x_{T}, y_{T}\right)} / \frac{\rho_{X}^{s}\left(x_{s}, y_{s}\right) / \rho_{X}^{s}\left(x_{T}, y_{T}\right)}{\rho_{X}^{T}\left(x_{s}, y_{s}\right) / \rho_{X}^{T}\left(x_{T}, y_{T}\right)}}
$$

If $\operatorname{ErBP}>1$, emission-reducing technology progress is likely to exist. The larger the value of $\operatorname{ErBP}$, the more significant the emission-reducing technology progress.

(EsBP) is

Similarly, the Malmquist index of energy-saving technology progress

$$
E s B P=\sqrt{D_{E} / D_{X}}=\sqrt{\frac{\rho_{E}^{s}\left(x_{s}, y_{s}\right) / \rho_{E}^{s}\left(x_{T}, y_{T}\right)}{\rho_{E}^{T}\left(x_{s}, y_{s}\right) / \rho_{E}^{T}\left(x_{T}, y_{T}\right)} / \frac{\rho_{X}^{s}\left(x_{s}, y_{s}\right) / \rho_{X}^{s}\left(x_{T}, y_{T}\right)}{\rho_{X}^{T}\left(x_{s}, y_{s}\right) / \rho_{X}^{T}\left(x_{T}, y_{T}\right)}}
$$

If $E s B P>1$, energy-saving technology progress is likely to occur, and the larger the value of $E s B P$ is, the more significant the energy-saving technology progress. As improvements in environmental quality simultaneously require energy saving and emission reduction, we define a comprehensive green technology progress index as

$$
E B P=E r B P \times E s B P=\sqrt{\left(D_{B} \times D_{E}\right) / D_{X}^{2}} .
$$

In addition to the proportion of foreign value added, we need to control for other indexes that may influence green technology progress.

Policy bias for non-state-owned enterprises obtained using the PSM method is zero. Therefore, we express the distortion for no biased policy as: 


$$
R=\left(\frac{1}{R_{N}+1}-\frac{1}{R_{\text {all }}+1}\right) \times\left(R_{\text {all }}+1\right)
$$

where $R$ refers to green technology disturbance, $R_{N}$ stands for the green technology progress rates of non-state-owned enterprises that are similar to stateowned ones, and $R_{\text {all }}$ is the green technology progress rate of state-owned enterprises.

\section{Model construction and index selection 4.1 PSM analysis}

We use PSM to identify non-state-owned enterprises similar to stateowned, using data from the China Industrial Enterprise Database. We selected enterprises for which national capital and collective capital occupy more than 50\% of total capital for state-owned ones, and for which a legal entity's capital and individual capital occupy more than 50\% of that for non-state-owned ones from 344,875 enterprises. Enterprises with more than 50\% Hong Kong, Macau and Taiwan capital and foreign capital are not included in our analysis. The following two conditions need to be satisfied for using the PSM method. The first is that data generation needs to be consistent(Cameron \& Trivedi, 2005); that is, data need to be generated at the same time. This can be easily realized using the industrial enterprise database, as enterprises report data at the same time. The second is there is a minimum sample size requirement(Abadie\&Imbens, 2002), but the share of state-owned enterprises among all types of enterprises declined from 23\% in 2001 to $2 \%$ in 2013. Nonetheless, this condition can be met, as there are 344,875 enterprises in the database, which enables using the ratio of one control to four treatment groups, as considered the most optimum by Abadie and Imbens (2002). It is worth noting that this ratio was not exceeded by the ratio of state-owned enterprises in 2001. Therefore, it is acceptable to adopt the PSM method for matching.

The largest challenge now is to simulate a condition contrary to reality: if one state-owned enterprise is to be transformed to a non-state-owned one, how much distortion will it face? As most enterprises are state- or non-state-owned, we need to use hypotheses to construct similar control and treatment groups for the analysis. Under the condition of large-scale data, PSM is based on two assumptions: non-confounding and mutually supportive. The former refers to stateand non-state-owned enterprises facing different distortion degrees due to different enterprise types, while the latter refers an overlap in the scope of matching scores for the two types of enterprises.

Under a traditional planned economy, there are apparent policy differences between state- and non-state-owned enterprises, and the implementation of policies is usually based on enterprise size, factor intensity, and industrial characteristics, so 
Biased Policy, Human Capital Distribution and Green Technical Progress

we may deem that this point satisfies the non-confounding assumption. Along with the recent development of marketization, market competition has been taken into consideration for designing government policies. Therefore, we assume that stateand non-state-owned enterprises can be compared on the premise of fixed size, same industry, same area, and similar input factor structure, thus controlling for all variables except policy to make the analysis results more reliable. Green technology distortion faced by state- and non-state-owned enterprises with the same propensity score will mainly result from biased policies.

We select data from 2001 to 2013 for our analysis, and set up a probit model to differentiate between state- and non-state-owned enterprises. The dummy variable is $\mathrm{D}=0$ or 1 , indicating whether the enterprise is state-owned or not. Explanatory variables include human capital input (L), location of enterprise (D1), industry of enterprise (D2), and enterprise scale (Scale). Although there are many variables that can describe enterprise characteristics, we only need to choose the main ones, to acquire more matching samples and avoid disturbing the matching efficiency of our models. When comparing state- and non-state-owned enterprises, the estimated scores for propensity $\mathrm{P}(\mathrm{x})$ will be used for matching, and theprobit model will be used to estimate the representation similarity of each enterprise, thus matching similar enterprises from the two groups. Thus, we set the matching model as:

$$
\tau_{L}=[(Y(1) \mid D=1)-(Y(0) \mid D=0)] \mid P(x),
$$

where $\tau_{L}$ refers to the differences in human capital input distortion between these two types of enterprises after matching, $P(x)$ is the propensity score; $\mathrm{D}=1$ stands for state-owned enterprises, $\mathrm{D}=0$ for non-state-owned enterprises, $\mathrm{Y}(1)$ represents the distortion faced by state-owned enterprises, and $\mathrm{Y}(0)$ the distortion faced by non-state-owned enterprises. We take human capital as a variable for matching.

We adopt the one-to-one matching method that takes human capital as the criterion variable and controls enterprises' features including industry, region, and size to find non-state-owned enterprises with similar natural qualities that matched to state-owned enterprises. Matching is carried out as per propensity scores that are acquired from the regression of explanatory variables, and then an equilibrium test is conducted as per matching results. There is a significant difference in quantity between the two enterprise types before matching, which is significant in all years. However, after matching, the difference was reduced by $95 \%$. The original assumption of no differences between these two types of enterprises cannot be refuted, indicating that state- and non-state-owned enterprises are matched. 
Malin Song, Shuhong Wang, Tomas Baležentis

\subsection{Test for disturbance of human capital distribution on green technology}

According to the above analysis, we set up the regression model of human capital distribution $(L)$ to green technology progress as:

$$
G T P=\alpha_{0}+\alpha_{1} L+\alpha_{2} \tau+\beta Z+\varepsilon,
$$

where $G T P$ stands for green technology progress and $L$ refers to human capital distribution. The ratio of $R \& D$ expenses to total fixed assets is taken as the $R \& D$ input of the enterprise, and then divided by the labor force quantity to represent the R\&D input per unit of labor force, as a substitute for the human capital distribution index. The higher the R\&D input per unit of labor force is, the higher the human capital distribution in the enterprise. $Z$ is the control variable, including the industrial sector and region of the enterprise, market competition intensity $(C)$, enterprise scale (Scale), comparative advantage of enterprise $(R C A) ; \varepsilon$ is the random error term. Hereinafter, we will explain each respective index.

There is still no unified index for measuring market competition intensity. Januszewski (2002) use the deciding degree of price by the market for measurement, but there are great differences among different industries and areas. The ratio of governmental price guidance in some areas may be high due to restrictions of the industrial structure. Beiner et al. (2011) use the marketization index for measurement, which describes the perfect degree of the market, something that is difficult to reflect from inside the market. Hence, we tried to construct an index suitable to measure the enterprise's market competition intensity.

Market competition intensity is decided by the competitiveness of an enterprise in the market and its degree of concentration. The higher the competitiveness, the smaller the impact of market competition. Moreover, the higher the concentration degree, the higher the market competition intensity. Enterprise market competitiveness can be thus calculated using the ratio of cash flow growth rate to total asset growth rate, through which the market competition intensity of an enterprise can be expressed by the reciprocal of enterprise competitiveness. The stronger the enterprise competitiveness, the smaller the pressure of market competition on the enterprise.

If there are many enterprises with high competitiveness in the market, the competition intensity of the market will be high. That is, if competitive enterprises concentrate in a certain area, then the market competition intensity in this area will be high.

The degree of market concentration $(E)$ is an index used to measure the intensity of competition. The higher the degree of industrial concentration, the fiercer the competition will be, due to the impacts of external economies of scale. According to the definitions of Naughton (1999) and Young (2000), we use the Hoover coefficient and location entropy to measure this index. This coefficient can 
be expressed as the share of output value of one industry in one area to the national total industrial output value; but, first, the location entropy needs to be calculated as:

$$
E_{i}=s_{i j} / s_{i},
$$

where $s_{i j}=q_{i j} / q_{j}$ represents the ratio of the output value of industry $i$ in region $j$ to the total industrial output value in region $j$ and $s_{i}=q_{i} / q$ the proportion of the output value of industry $i$ to the national total industrial output value. If $E_{i}>1$ , industry $i$ in this region is in a status of clustering. If $E_{i}<1$, industry $i$ is dispersing. We classify the location entropies from small to large, placing the cumulative percentage of industry $i\left({ }^{s_{i j}}\right)$ on the vertical axis and the cumulative percentage of all regions $\left({ }^{S_{j}}\right)$ on the horizontal. If industry $i$ is evenly distributed in all regions, the curve will coincide with the 45-degree line from the origin. However, if there is clustering, the curve will bend to the horizontal axis. The higher the degree of clustering, the greater the radian will be. The Hoover coefficient is calculated by the ratio of the area of the curved triangle to the evenly distributed area.

Market competition intensity is the product of enterprise competitiveness in the market and its degree of concentration. It can be expressed as:

$$
\text { Comp }=E C \times E \text {. }
$$

Large-scale enterprises with a low degree of competition have higher innovation potential because they have large quantities of internal resources, such as capital, technology, and researchers. Internal funds in large-scale enterprises can better support multiple R\&D activities, control new product prices, and undertake R\&D risks. Additionally, large-scale enterprises face less market uncertainty and can raise funds more easily. Hence, we select large-, medium-, and small-scale enterprises as explanatory variables (dummies).

We build an index for enterprises to measure relative comparative advantages:

$$
R C A=\frac{X_{i j t} / \sum X_{i j t}}{X_{i t}^{w} / \sum X_{i t}^{w}},
$$

where $X_{i j t}$ is the sale amount of enterprise $j$ in industry $i$ in year $t$ and $X_{i t}^{w}$ is the gross global sales amount in industry $i$ in year $t$. If $R C A<1$, the amount of enterprise $j$ 's sales in year $t$ is smaller than the average amount of industry $i$ in that year. In this case, the enterprise has a comparative advantage. As for the 
Malin Song, Shuhong Wang, Tomas Baležentis

enterprises in this study, since they have similar economic and policy conditions, having a comparative advantage in the entire industry means more advanced technology and greater productivity.

\section{Results}

The results of estimating (19) are shown in Table 1. The first column lists the variables, the second to the fourth columns present the estimation results of the differential GMM method, and the fifth to the seventh columns the estimation results of GMM.

The model tested the effect of human capital distortion on green technology under fixed time, industry, and area. From Table 1, human capital distortion has a negative effect on green technology progress: the higher the degree of human capital distortion, the greater its disturbance to green technology. This point can also be visualized from the human capital distribution index. The estimation coefficient of the human capital distribution is negative, meaning that the relationship between human capital distribution and green technology progress is negative. More material capital input, more advanced production equipment, and higher productivity are all unfavorable characteristics for enterprises to develop green technologies. This may indicate that material capital input is aimed at productive technology, while green technologies are energy-saving and emission reduction technologies that only increase enterprises' R\&D costs instead of increasing output. In this case, enterprises will definitely develop their own competitiveness advantage, neglecting the environment. On the other hand, increasing material capital input will require hiring highly skilled laborers who will stimulate productive technology rather than green technology. Therefore, the estimation coefficient of human capital distribution being negative is inevitable.

The estimation results for competition degree and green technology are also negative, indicating that enterprises with a higher degree of competition will be more unwilling to engage in $\mathrm{R} \& \mathrm{D}$ for green technology. However, the estimation coefficient of this index is only significant at the $10 \%$ level, indicating a low fitting accuracy. Regarding enterprise scale, be it small or large, enterprises will all carry out relevant inputs. This may be related to the implementation of relevant environmental regulations in every area. Enterprises cannot discharge pollutants without limitation, and pollution will be treated as a production cost of enterprises considering environmental regulations. However, due to their monopoly characteristics, that is, bureaucracy and multiple hierarchies, large-sized enterprises are not enthusiastic about technological R\&D. Small-sized enterprises, due to the high pressure of market competition, will place most of their efforts toward developing productive technologies rather than green ones. Therefore, from the estimation coefficient, middle-sized enterprises have the highest enthusiasm for green technology development. 
Biased Policy, Human Capital Distribution and Green Technical Progress

Table1. Preliminary models of human capital distribution under the green technology

\begin{tabular}{|c|c|c|c|c|c|c|}
\hline Variables & (1) & (2) & (3) & (4) & (5) & (6) \\
\hline \multirow{2}{*}{$C$} & $0.589 * * *$ & $0.671 * * *$ & $0.187 * * *$ & $0.677 * * *$ & $0.598 * * *$ & $0.209 * * *$ \\
\hline & (18.10) & (20.94) & (14.26) & (15.69) & $(17.21)$ & (20.68) \\
\hline \multirow{2}{*}{$L$} & $-5.218 * * *$ & $-4.951 * * *$ & $-5.332 * * *$ & $-6.491 * * *$ & $-6.184 * * *$ & $-4.218 * * *$ \\
\hline & $(-6.15)$ & $(-4.88)$ & $(-4.59)$ & $(-5.11)$ & $(-6.17)$ & $(-4.08)$ \\
\hline \multirow{2}{*}{$\tau$} & $-0.098 * *$ & $-0.078 * *$ & $-0.042 * *$ & $-0.063 * * *$ & $-0.088 * * *$ & $-0.094 * * *$ \\
\hline & $(-2.41)$ & $(-2.36)$ & $(-1.99)$ & $(-3.63)$ & $(-4.70)$ & $(-3.08)$ \\
\hline \multirow{2}{*}{ сотp } & $-1.805^{*}$ & $-1.264^{*}$ & $-1.617^{*}$ & $-1.571^{*}$ & $-1.496^{*}$ & $-1.338^{*}$ \\
\hline & $(-1.48)$ & $(-1.76)$ & $(-1.92)$ & $(-1.71)$ & $(-1.95)$ & $(-1.35)$ \\
\hline \multirow{2}{*}{ Scale-B } & $0.294 * * *$ & & & $0.174 * * *$ & & \\
\hline & $(6.54)$ & & & $(3.77)$ & & \\
\hline \multirow{2}{*}{ Scale-M } & & $0.398 * * *$ & & & $0.208 * * *$ & \\
\hline & & $(7.22)$ & & & $(5.29)$ & \\
\hline \multirow{2}{*}{ Scale-S } & & & $0.257 * * *$ & & & $0.199 * * *$ \\
\hline & & & $(5.11)$ & & & $(4.66)$ \\
\hline \multirow{2}{*}{$R C A$} & $0.386 * * *$ & $0.333 * * *$ & $0.340 * * *$ & $0.344 * * *$ & $0.366^{* * * *}$ & $0.334 * * *$ \\
\hline & $(20.64)$ & (19.34) & $(18.36)$ & $(21.24)$ & $(20.47)$ & $(18.22)$ \\
\hline Time fixed & yes & yes & yes & yes & yes & yes \\
\hline Industry fixed & yes & yes & yes & yes & yes & yes \\
\hline Region fixed & yes & yes & yes & yes & yes & yes \\
\hline$A D J-R^{2}$ & 0.95 & 0.89 & 0.88 & 0.92 & 0.86 & 0.88 \\
\hline Hausman test & 45.15 & 48.33 & 46.18 & 50.71 & 43.40 & 44.40 \\
\hline $\mathrm{P}$-value & 0.000 & 0.000 & 0.000 & 0.000 & 0.000 & 0.000 \\
\hline
\end{tabular}

Note: Scale-B represents whether the enterprise is large-sized, Scale-M is for medium-sized enterprises, and Scale-S for small-sized. The values between parentheses are the t-statistics of regression coefficients. *, **, and $* * *$ respectively represent passing the test under the $10 \%, 5 \%$, and $1 \%$ significance levels.

Demand for consumer goods had been transforming from "good quality products" to "environmentally-friendly products with low carbon emissions" due to an increasing public attention towards environmental quality. As such, the products of enterprises have to ensure not only quality but also energy saving and 
Malin Song, Shuhong Wang, Tomas Baležentis

environmental protection. Developed countries condition Chinese enterprises in that they only import products that satisfy their national environmental protection standards. Therefore, not only production and market share, but also environmental protection has to be considered when measuring the comparative advantages of enterprises. If the carbon emissions of an enterprise are not standard, the share of the enterprise in its industry will be hindered. We identify this trend through measurement, using the RCA index. From the estimation coefficient, the higher the comparative advantage, the stronger the motive for $\mathrm{R} \& \mathrm{D}$ of green technology. Therefore, the estimation coefficient of this index is positive.

We separate state- from non-state-owned enterprises for estimation and introduce the quadratic term of market competition. Human capital distortion of state-owned enterprises is $\tau_{L}$ and that of non-state-owned ones is $\tau_{C L}$. The estimation results are shown in Table 2.

After differentiating between state- and non-state-owned enterprises, the regression results present significant differences. From Table 2, the regression coefficient of human capital distribution in state-owned enterprises is significantly negative, while that of non-state-owned ones is positive, indicating that human capital in state-owned enterprises is not favorable to $R \& D$ in green technologies. These enterprises are protected by biased policies, operating in a comfortable environment. With governmental support, they have limited consideration for environmental protection and technological progress. Conversely, non-state-owned enterprises have no preferential policies and a tougher financing environment, having to place more efforts into green technology development. Moreover, they are more likely to be affected by market competition. Therefore, to improve competitiveness, they increase their own technological levels.

After introducing the quadratic term of market competition intensity, its regression coefficient became significantly positive, while that of the primary term is negative. This indicates that there is a U-shaped relationship between market competition intensity and green technology progress. When the competition intensity is not fierce, a higher market intensity will hinder the development of green technology progress. However, when there is fierce competition, due to decreasing returns to scale, benefits from enterprises devoting production factors to productive technology will be less than those from green technology. Thus, green technology progress will be promoted. 
Biased Policy, Human Capital Distribution and Green Technical Progress

Table2. Human capital distribution model based on green technology

\begin{tabular}{|c|c|c|c|c|c|c|}
\hline Variables & \multicolumn{3}{|c|}{ State-owned enterprises } & \multicolumn{3}{|c|}{ Non-state-owned enterprises } \\
\hline \multirow{2}{*}{$C$} & $0.412 * * *$ & $0.781 * * *$ & $0.557 * * *$ & $0.487 * * *$ & $0.618 * * *$ & $0.604 * * *$ \\
\hline & $(12.05)$ & $(17.11)$ & $(13.75)$ & (14.29) & $(16.38)$ & $(15.22)$ \\
\hline \multirow{2}{*}{$L$} & $-10.551 * * *$ & $-8.373 * * *$ & $-8.559 * * *$ & $2.05^{*}$ & $3.18^{* *}$ & $2.54 * *$ \\
\hline & $(-14.21)$ & $(-12.58)$ & $(-13.96)$ & $(1.86)$ & $(2.52)$ & $(2.18)$ \\
\hline \multirow{2}{*}{$\tau_{L}$} & $-0.073 * *$ & $-0.057 * *$ & $-0.064 * *$ & & & \\
\hline & $(-2.17)$ & $(-2.37)$ & $(-2.88)$ & & & \\
\hline \multirow{2}{*}{$\tau_{C L}$} & & & & $-0.077 * * *$ & $-0.075^{* * *}$ & $-0.076 * * *$ \\
\hline & & & & $(-6.52)$ & $(-6.38)$ & $(-6.39)$ \\
\hline \multirow{2}{*}{ comp } & $-0.359 * * *$ & $-0.348 * *$ & $-0.428 * *$ & $-0.268 * * *$ & $-0.384 * * *$ & $-0.422 * * *$ \\
\hline & $(-8.11)$ & $(-7.16)$ & $(-8.19)$ & $(-8.33)$ & $(-9.37)$ & $(-7.28)$ \\
\hline \multirow{2}{*}{$\operatorname{comp}^{2}$} & $0.105 * * *$ & $0.144 * * *$ & $0.138 * * *$ & $0.132 * * *$ & $0.177 * * *$ & $0.192 * * *$ \\
\hline & $(3.99)$ & $(4.10)$ & $(3.83)$ & (3.99) & $(4.38)$ & $(4.33)$ \\
\hline \multirow{2}{*}{ Scale-B } & $0.381 * * *$ & & & $0.171^{* * * *}$ & & \\
\hline & $(4.93)$ & & & $(7.19)$ & & \\
\hline \multirow{2}{*}{ Scale-M } & & $0.436^{* * * *}$ & & & $0.218^{* * * *}$ & \\
\hline & & $(6.11)$ & & & $(6.17)$ & \\
\hline \multirow{2}{*}{ Scale-S } & & & $0.224 * * *$ & & & $0.177 * * *$ \\
\hline & & & $(6.19)$ & & & $(3.18)$ \\
\hline \multirow{2}{*}{$R C A$} & $0.521 * * *$ & $0.568 * * *$ & $0.554 * * *$ & $0.439 * * *$ & $0.464 * * *$ & $0.420 * * *$ \\
\hline & $(15.17)$ & $(16.24)$ & $(12.30)$ & (14.08) & $(16.77)$ & $(15.32)$ \\
\hline Time fixed & yes & yes & yes & yes & yes & yes \\
\hline Industry fixed & yes & yes & yes & yes & yes & yes \\
\hline Region fixed & yes & yes & yes & yes & yes & yes \\
\hline$A D J-R^{2}$ & 0.85 & 0.86 & 0.86 & 0.87 & 0.91 & 0.84 \\
\hline Hausman test & 53.08 & 56.32 & 57.28 & 54.16 & 55.91 & 51.27 \\
\hline P-Value & 0.000 & 0.000 & 0.000 & 0.000 & 0.000 & 0.000 \\
\hline
\end{tabular}

Note: Scale-B represents whether the enterprise is large-sized, Scale-M is for medium-sized enterprises, and Scale-S for small-sized. The values between parentheses are the t-statistics of regression coefficients. *, **, and *** respectively represent passing the test under the $10 \%, 5 \%$, and $1 \%$ significance levels. 
Malin Song, Shuhong Wang, Tomas Baležentis

\section{Conclusions and policy implications}

This study established a green technology index to measure the green technology progress of enterprises. The production decision-making of stateowned enterprises is definitely affected by the distortion of human capital distribution, so that the green technology progress rate can be distorted. The proposed measurement model measured the biased policy, human capital distribution distortion, and green technology progress, finding that the effect of biased policy did exist as a degree of human capital distribution distortion in stateowned enterprises, which resulted in increasing biased policies and green technology progress being greatly affected. These findings are significant to the current economic development in China as follows.

First, the distortion of distribution from biased policies does exist. Thus, to eliminate biased policies, a fair competitive environment should be established. Perfect market competition mechanisms should be cultivated to increase per capita output, improve trade conditions, increase types of consumer products, and finally restore and reach the required profit-making level. Meantime, non-state-owned enterprises should be encouraged, subsidized, and provided a fairer financing environment, while a competitive atmosphere and human capital flow mechanism should be created to weaken barriers between state- and non-state-owned enterprises.

Second, the human capital distribution distortion from biased policies greatly hinders the development of green technologies in China. Moreover, such a distorted distribution of human capital is also a reason for low production efficiency in enterprises. Therefore, China needs to enhance its structural reform and establish talent safeguard mechanisms to ensure an optimum flow of highly skilled laborers. Talent evaluation and employment systems also need to be perfected and put into practice to guarantee immediate rights and vital interests of human resources.

Third, improving enterprise productivity should be the fundamental starting point of enterprise reforms. The blind expansion of enterprises has resulted in excessive productivity over the past five years, which further stimulated the government compensation policies to enterprises and resulted in increased productivity losses. In the era of the New Normal, excessive productivity has become a problem China must face in the process of economic growth. Adjustments must be made on the policy level, and the process of de-capacity must be accompanied by eliminating biased policies.

Finally, the elimination of biased policies needs classification and enterprise reforms, and it should be promoted in different sequences. In industries that state-owned enterprises and non-state-owned ones both exist, a market rule should be carried out to eliminate enterprises with low efficiency and heavy pollution. The separation of enterprises from the administration, government, and capital, and the separation of ownership and management should be accelerated to 
Biased Policy, Human Capital Distribution and Green Technical Progress

have efficient state-owned enterprises become stronger, better, and larger in a fair competitive environment, while fully exerting the superiority of the socialist market economy.

Acknowledgements

This work was supported by the National Natural Science Foundation of China [Grant No. 71601170],Projects in Philosophy and Social Science

Research of the Ministry of Education of China [Grant No. 16YJC630123], and China Postdoctoral Science Foundation

[Grant Nos.2015M570613and2017T100514].

\section{REFERENCES}

[1] Abadie, A., Imbens, G. (2002), Simple and Bias-corrected Matching Estimators for Average Treatment Effects. National Bureau of Economic Research Cambridge, Mass., USA, Working Paper;

[2] Acemoglu, D., G. Gancia, F. Zilibotti. (2015), Offshoring and Directed Technical Change. American Economic Journal - Macroeconomics, 7, 84-122;

[3] Beiner, S., Schmid, M.M., Wanzenried, G. (2011), Product Market Competition, Managerial Incentives, and Firm Valuation. European Financial Management, 17(2): 331-366;

[4] Brandt, L., Biesebroeck, J.V., Zhang, Y. (2012), Creative Accounting or Creative Destruction? Firm-level Productivity Growth in Chinese Manufacturing. Journal of Development Economics, 97(2): 339-351;

[5] Brandt, L., Tombe, T., Zhu, X.D. (2013), Factor Market Distortions across Time, Space, and Sectors in China. Review of Economic Dynamics, Vol. 16, No. 1, pp. 39-58;

[6] Cameron, A.C. Trivedi, P.K. (2005), Microeconometrics: Methods and Applications. Cambridge University press;

[7] Chari, V.V., Kehoe, P.J., McGrattan, E.R. (2007), Business Cycle Accounting. Econometrica, 75(3): 781-836;

[8] Chiara P., Ivete S., Gomes F. (2011), Competition and Innovation in Luxembourg. Journal of Industry Competition and Trade, 12(1): 93-117;

[9] Dimelis, S., Louri, H., (2002), Foreign Ownership and Production Efficiency: A Quantile Regression Analysis; Oxford Economic Papers;

[10] Dodgson, M., Rothwell, R. (1994), The Handbook of Industrial Innovation. Edward Elgar, UK; 
Malin Song, Shuhong Wang, Tomas Baležentis

[11] Fang, S.T., Ji, X., Ji, X.H., Wu, J. (2018) Sustainable Urbanization Performance Evaluation and Benchmarking: An Efficiency Perspective; Management of Environmental Quality, 29(2), 240-254;

[12] Hsieh, C.T., Klenow, P.J. (2009), Misallocation and Manufacturing TFP in China and India. Quarterly Journal of Economics, 124(4): 1403-1448;

[13] Januszewski, S.I., Koke, F. J., Winter, J. K., (2002), Product Market Competition, Corporate Governance and Firm Performance: An Empirical Analysis for Germany. Research in Economics, 56: 299-332;

[14] Jones, C.I. (2011), Intermediate Goods and Weak Links in the Theory of Economic Development. American Economic Journal: Macroeconomics, Vol. 3, No. 2, 2011, pp. 1-28;

[15] Naughton, B. (1999), How much Can Regional Integration Do to Unify China's Market? University of California at San Diego Mimeo, 1999;

[16] Qi, S.Z., Li, Y. (2017), Threshold Effects of Renewable Energy Consumption on Economic Growth under Energy Transformation. Chinese journal of population, resources and environment, 15(4): 312-321;

[17] Song, M.L., Wang, S.H. (2016), Can Employment Structure Promote Environment-biased Technology Progress? Technological Forecasting and Social Change, 112: 285-292;

[18] Song, M.L., Wang, S.H., Wu, K.Y. (2016), Environment-biased Technology Progress and Industrial Land Use efficiency in China's New Normal. Annals of Operations Research, DOI 10.1007/s10479-016-2307-0;

[19] Sunku H. (2010), Predation, Competition, Comparison and Innovation. Economics Letters, pp: 122-124;

[20] Wurgler, J. (2000), Financial Markets and the Allocation of Capital. Journal of Financial Economics, Vol. 58, No. 1, pp. 187-214;

[21] Young, A. (2000), The Razor's Edge: Distortions and Incremental Reform in the People's Republic of China. Quarterly Journal of Economics. 115, 1091-1135;

[22] Zeng, S.Z. (2017), Pythagorean Fuzzy Multiattribute Group Decision Making with Probabilistic Information and OWA Approach; International Journal of Intelligent Systems, 2017, 32(11): 1136-1150;

[23] Zhang N, Choi Y. (2014), A Note on the Evolution of Directional Distance Function and its Development in Energy and Environmental Studies 1997-2013. Renewable \& Sustainable Energy Review, 33: 50-59;

[24] Zhao, Q.R., Chen, Q.H., Xiao, Y.T., Tian, G.Q., Chu, X.L., Liu, Q.M. (2017), Saving Forests through Development? Fuel Wood Consumption and the Energy-ladder Hypothesis in Rural Southern China; Transformations in Business \& Economics 16(3) 199-219. 